
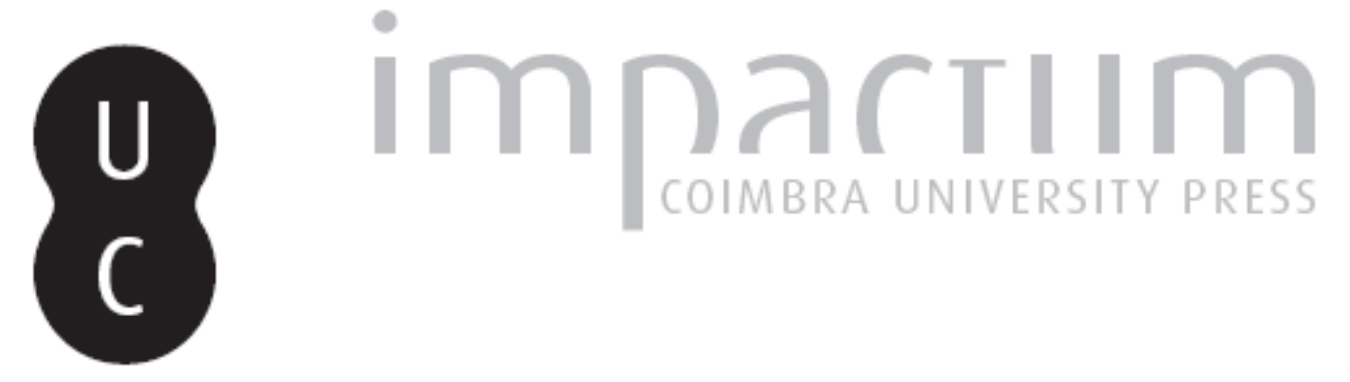

\title{
El retorn al polític com a fonamentació de la ciutat
}

Autor(es): $\quad$ Monserrat-Molas, Josep

Publicado por: Annablume Clássica

URL persistente:

URI:http://hdl.handle.net/10316.2/24512

DOI:

DOI:http://dx.doi.org/10.14195/1984-249X_11_1

Accessed : $\quad$ 26-Apr-2023 15:34:34

A navegação consulta e descarregamento dos títulos inseridos nas Bibliotecas Digitais UC Digitalis, UC Pombalina e UC Impactum, pressupõem a aceitação plena e sem reservas dos Termos e Condições de Uso destas Bibliotecas Digitais, disponíveis em https://digitalis.uc.pt/pt-pt/termos.

Conforme exposto nos referidos Termos e Condições de Uso, o descarregamento de títulos de acesso restrito requer uma licença válida de autorização devendo o utilizador aceder ao(s) documento(s) a partir de um endereço de IP da instituição detentora da supramencionada licença.

Ao utilizador é apenas permitido o descarregamento para uso pessoal, pelo que o emprego do(s) título(s) descarregado(s) para outro fim, designadamente comercial, carece de autorização do respetivo autor ou editor da obra.

Na medida em que todas as obras da UC Digitalis se encontram protegidas pelo Código do Direito de Autor e Direitos Conexos e demais legislação aplicável, toda a cópia, parcial ou total, deste documento, nos casos em que é legalmente admitida, deverá conter ou fazer-se acompanhar por este aviso.

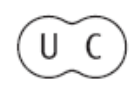



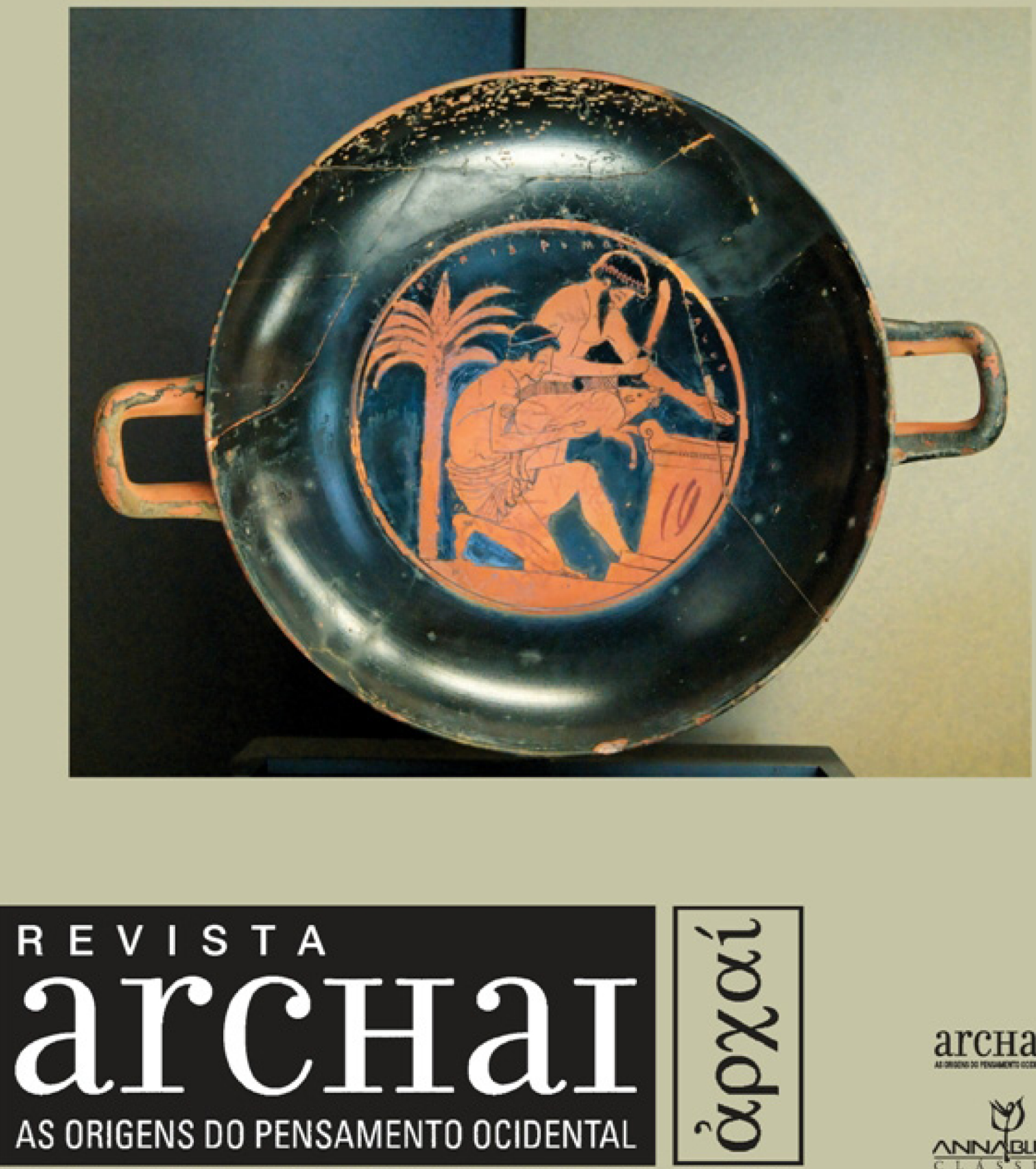

ARCHAI JOURNAL: ON THE ORIGINS OF WESTERN THOUGHT

arcHaI凰

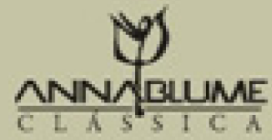




\title{
EL RETORN AL POLÍTIC COM A FONAMENTACIÓ DE LA CIUTAT
}

\author{
Josep Monserrat-Molas*
}

MONSERRAT-MOLAS, J. (2013). El Retorn al Polític com a Fonamentació de la Ciutat. Archai, n. 11, jul-dez, p. 11-20.

RESUM: Després del centre de El polític, dedicat a la justa

* Universitat de Barcelona, jmonserrat@ub.edu. mesura, el diàleg imposa el «retorn al polític» i ja no se separarà més d'aquesta comesa. Es procedirà, en primer lloc a depurar les arts concausants; després se separaran les diferents menes de servidors de la ciutat, per tal d'arribar a veure que els rivals del polític conformen un conjunt de difícil separació. Caldrà, abans de prosseguir amb la divisió, atendre als tipus de règim politic per veure quin paper hi juga el saber politic. El resultat d'aquest primer moment del retorn al polític pren la figura de la descoberta dels fonaments de la ciutat.

PARAULES CLAU: Plató. El Polític. Fonaments de la ciutat.

ABSTRACT: Following the centre of Politicus, devoted to the right measure, the dialogue commands the «return to the statesman» and will no longer relinquish such mission. It proceeds, in the first place, to the depuration of co-causant crafts; afterwards, it goes on to discern the different classes of state servants so as to gain an insight into how rivals of the statesman make up a tangled set, one that is hard to set apart. It will prove necessary, before going forth in the division, to give heed to the different types of political regimes so that the role of political wisdom can be revealed. The result of this first moment of the return to the statesman adopts the figure of an unveiling of the foundations of the city.

KEY WORDS: Plato. Statesman. Foundations of the city.
El centre de El polític, dedicat a la justa mesura, es clou amb l'acord dels dos protagonistes que, pel que fa a la mesura, és suficient. Passa sovint en altres llocs del diàleg que aquesta «comunitat de parers» no és pas cap garantia d'encert. Sigui com sigui, el diàleg imposa el «retorn al polític» $i$ ja no se separarà més d'aquesta comesa.

En el primer moment d'aquest retorn veurem com es procedeix a la manera del tissatge, és a dir, a separar les arts concausants de les arts causants en la figura encara no prou depurada del pastor del ramat que accepta voluntàriament el govern ( $\$ 1$. «La depuració de les arts concausants: els fonaments materials»). Després se separaran les diferents menes de servei (§2. «Separació dels servidors de la ciutat»), per tal d'arribar a veure que els rivals del polític se situen entre aquests $i$ conformen un conjunt de difícil separació ( $\$ 3$. «Valoració i ruptura de la dièresi»). Caldrà, abans de proseguir amb la divisió, atendre als tipus de règim polític $i$ $d^{\prime}$ individus que trobem per veure quin paper hi juga el saber polític. El resultat d'aquest primer moment del retorn al polític pren la figura de la descoberta dels fonaments de la ciutat. 


\section{§1. La depuració de les arts concausants: els fonaments materials}

Després de la justa mesura s'inicia el retorn al polític amb l'aplicació de l'exemple i paradigma del tissatge, concretament des del punt que s'havia assolit, la distinció d'arts causants i concausants. ${ }^{1}$ El jove Sòcrates ho troba bé i s'incorpora a la feina. Després del mite s'havien ja separat de la figura del rei moltes arts que afecten el seu àmbit, especialment totes aquelles que prenen cura de ramats per la força. Restava encara separar-lo de les arts que pertanyen a les causes $i$ a les causes auxiliars.

El Foraster sempre s'havia referit abans als ramats (perì tàs agélas), mentre que es refereix d'ara endavant, a la ciutat (katà pólin autén). Hi ha consciència de què es passarà a tractar d'un àmbit nou, un àmbit més «sociològic» que no pas «biològic». Es presenta, però, un problema. La dièresi, diu el Foraster, no pot efectuar-se dividint en dos. Aquest fet sembla anar contra la norma imposada, $i$, en conseqüència, cal justificar el canvi en l'aplicació del mètode, però aquesta explicació queda ajornada i simplement es passa a dividir «per membres, com una víctima sacrificial». És important destacar que en el mateix inici de la consideració que ara s'enceta, aparegui el sacrifici. Amb aquesta imatge, les arts que han de ser dividides pròximament es comparen a un cos, a una totalitat orgànica, i també l'anàlisi amb quelcom sagrat, a saber, el sacrifici, situat en l'àmbit de la religiositat.

En un primer moment es recupera la figura confusa del rei i del pastor de ramats. Per aclarir la primera és necessari, diu el Foraster, separar les arts concausants de les altres arts. Un cop aclarit que en l'aplicació d'aquesta nova manera de divisió es procedeix com abans amb el tissatge, primer se separen aquelles que proporcionen eines ${ }^{3}$, sense les quals no hi podria haver ni ciutat ni política. La ciutat apareix primer establerta com a àmbit de la dièresi i de la construcció o producció. Després, se separa l'art dels recipients. En tercer lloc, l'art dels vehicles o de qualsevol estri de transport. La quarta mena d'art proporciona l'abric: s'inclouen aquí vestit, armes, muralles, cases, etc. Aquestes coses les proporciona l'arquitectura i el tissatge i queda clar que «cal tenir-ho més correctament per això que no pas per polític». El text mostra explícitament que no hi ha confusió entre allò que cal aclarir i allò que s'utilitza com a paradigma (política i tissatge, respectivament).

El cinquè art concausant que se separa correspon a tot allò que pertany a l'ornamentació, a la pintura, a la música, a tot allò ordenat al nostre plaer: en un sol nom, diversió (paígnión), nom que s'aplica a tot allò que es fa per joc, sense cap altre interès. El jove afegeix que ho comprèn suficientment, que cada vegada ho veu més clar. En aquest darrer cas hom pot pensar si aquesta clarividència no torna a ser per motiu de la seva edat. ${ }^{4}$ Recordem que el pastor de la primera dièresi s'encarrega del parteratge, dels jocs i de la música per entretenir o calmar el ramat (268b).

El sisè art és aquell que proporciona els materials que utilitzaran totes les altres arts per a la seva comesa. Es tracta del treball de l'or, de la plata, de les fustes, de la llana, de l'escorça... Això s'anomenarà «possessió originària i no composta», que tampoc no és obra del saber reial. Noti's que es parla de saber reial (basilikês epistémes 288e5-6), mentre que fins ara es referia també a l'art polític. També aquest sisè art és un art auxiliar (concausant) de les arts concausants, el que proporciona la matèria primera a les altres arts (Plató no té una paraula fixada per al que nosaltres anomenem matèria). ¿Proporciona aquest art els materials a les altres arts de la mateixa manera que els proporciona a l'art reial o polític? ¿És la naturalesa la que propocionaria el material a la política o cal que aquesta se'l procuri? No seria estrany pensar a partir d'aquí la diferència fonamental entre la concepció aristotèlica de l'home com a animal polític i el que aquest text presentaria: la ciutat $i$ els ciutadans com a artefactes de la política. ${ }^{5}$

El setè art és el de l'alimentació (trophón), que inclou el conreu, la cacera, la gimnàstica, la medicina i la cuina. El que procura aquest art és envigorir el cos (tó sôma). Fixem-nos que precisament ara, després d'haver parlat de la necessitat de fornir materials per a la política, estem «tocant» el cos que esdevindrà polític. És precisament en aquest setê ${ }^{6}$ art on trobem les característiques de l'ocupació del
1. Un senyal del fet que comença una nova part el dóna l'aparició de pálin a 287b1. Rosen (1995) creu que aquí comença la darrera part del diàleg. La seva interpretació menysté les parts que se succeiran a partir d'ara. Vegeu sobre la qüestió de la divisió del diàleg en parts diferents i com aquesta divisió l'estructura, Monserrat (2003).

2. Cf. Fedre 265e, on es divideix segons les juntures naturals no arbitràriament per la meitat; també Fileb 16d.

3. Són molt útils en tot aquest passatge les notes que acompanyen la traducció de Skemp (1942).

4. Vegeu Miller $(2004,84)$. Parlant del Foraster: «Can the same speaker who has given us diairetic jokes and a 'playful' (268d) cosmo-theological myth really dichotomize play and seriousness in this way?»

5. Qui ha fet més esment d'Aristòtil ha estat Rosen (1995) en tot el seu treball. Cf. Aristòtil Política I 10, 1258a 21-23: «La política no fabrica homes, els rep de la naturalesa i després els utilitza». La concepció que critica Aristòtil és protagòrica.

6. Rosen (1995, p. 142) s'adona que aquesta és la primera llista de set ítems que el Foraster proposa en aquesta setena part del diàleg. A part d'aquesta de les possessions, hi haurà encara la dels servidors i la dels règims polítics. Aquest autor creu que les dues darreres poden considerar-se també possessions del rei. 
pastor que prenia cura del ramat: l'alimentava, en procurava la reproducció, l'entretenia, el defensava. Això correspon als quatre darreres arts que hem separat. Les tres primeres (les que proporcionen eines, recipients $i$ vehicles) no apareixen en la tasca del pastor. L'ordre està forçadament trastocat per tal de mantenir reunit allò de què s'ocupa el pastor.

Tot allò que es pot posseir, diu el Foraster, tret dels animals manyacs, s'ha enunciat en aquests set gèneres. La resta de coses que es posseeixen s'hi ha d'ajustar, si no els plau per força. Fixem-nos com actua la «neutralitat metòdica»: es tracta de fer encabir la realitat forçadament en un motlle. El Foraster indica, però, que l'ordre correcte hauria estat aquest altre (posem entre parèntesi el lloc que ocupava abans): i/ la forma primigènia (6), ii/ l'instrument (1), iii/ el recipient (2), iv/ el vehicle (3), v/ l'abric (4), vi/ la diversió (5), i vii/ el nodriment (7).

Si observem ambdós ordres ens adonarem que

7. Benardete $(1984,213 \mathrm{~s}) \mathrm{fa}$ notar que els termes usats pel Foraster en els elements de la llista són els mateixos amb els quals Timeu anomena les parts del cos humà en el diàleg que porta el seu nom. En particular, el cap és tò aggeîon, un recipient, el cos és tò ókhema, un vehicle, i la carn i la pell són tò próblema, una defensa o abric.

8. Aquesta idea havia estat suggerida abans, tot i que no portada a terme en la seva totalitat, per Goldschmidt (1947a 270-271). Dorter (1994) sembla desconèixer-ho

9. Miller (2004, 80-81) segueix l'argument de Schröder (1935)

10. Carta VII 344bc: «Perquè és necessari d'aprendre juntament aquestes coses, $i$ alhora la veritat i la falsedat a propòsit de la totalitat de l'ésser, amb una dedicació completa que es prolongui durant molt de temps, com he dit al començament. Si,

amb grans esforços, freguem

cadascun d'aquests factors amb els altres -els noms, els discursos, les visions $i$ les percepcions-, i ho sotmetem tot a refutacions fetes de bona fe, formulant preguntes i respostes sense malícia, a la fi tota cosa és il $\bullet$ luminada per la comprensió i la intel•ligència, sempre que ens hi apliquem tant com és humanament possible» [PLATÓ. Cartes. trad. R. Garrigasait. Barcelona, Fundació Bernat Metge, 2009]. generador del sisè al primer lloc de la llista. Hi ha una marcada vacil•lació sobre qui és qui proporciona la matèria de la política.

Comparada amb les divisions anteriors, una llista com aquesta amb prou feines sembla una divisió. Tenint present la distinció entre la via llarga i la via curta (265 i ss.), ens adonem que el Foraster usa aquí de la curta, a saber, l'articulació en gèneres en les seves espècies últimes sense biseccions intermediàries. Ara bé, K. Dorter suggereix que el Foraster podria haver fet una divisió dierètica posant, com suggereix la recapitulació, «els materials originals» (tò protogenés eîdos) en primer lloc. ${ }^{8}$ Sembla, doncs, que el Foraster podria haver definit el polític seguint la dièresi segons el mètode anteriorment utilitzat. ¿Per què no ho fa? M. Miller diu que el motiu és que vol alguna cosa més que aïllar el polític (2004, p. 76). També considera que el canvi de mètode és d'una gran importància, ${ }^{9}$ perquè assistim a una superació de la dièresi bifurcatòria per assolir un nivell superior en la comprensió del problema de la realitat. Ho compara amb les successives correccions dels discursos que es presenten en El convit i en la correcció que és La república respecte al seu llibre primer. La comparació de l'acció d’El polític amb un passatge del que es coneix com digressió filosòfica de la Carta VII ens sembla suggerent. ${ }^{10}$ Ara bé, si el que diu M. Miller és cert, i no dubtem que podria ser un senyal del camí filosòfic ofert al jove Sòcrates com a superació de les matemàtiques, el que encara queda per explicar és la paradoxa de per què aquest possible guany es mostra en el diàleg amb una aparent pèrdua de precisió. Pensem que l'aparent pèrdua de precisió es deu a no restar en l'àmbit «precís» de la mesura matemàtica.

\section{§2. Separació dels servidors de la ciutat}

El Foraster, deixades de banda les anteriors causes auxiliars del vertader art de la ciutat, passa aleshores a una altra consideració. Recordem que tot el que es podia posseir, excepte els animals manyacs, entrava en els anteriors set gèneres. L'adquisició dels éssers vius manyacs, diu, la comprendrà la cura de ramats tal com abans havia estat dividida, 
fent referència a la fallida dièresi del polític en el punt on es dividia en animals salvatges $i$ manyacs. Els esclaus en queden fora: en un primer moment ells tots sols, diferenciant-los dels animals manyacs (289b7). En un segon moment associant-los als servidors en general (289c4). ${ }^{11}$ La qüestió bàsica en aquesta separació és que sembla que se cercarà el polític o rei entre els que exerceixen un servei, mentre que en general s'hauria esperat que el servei quedés separat de l'art polític o reial, que seria més aviat un art del comandament, com es deia en la segona divisió (dividint l'especulatiu en crític i imperatiu, 259-260). Cal insistir que els rivals del rei es localitzaran a partir de la mateixa classe a la qual pertanyen també els esclaus o servidors més que en la classe dels homes lliures. Això deixa obertes les següents consideracions: o bé (1) el polític pertany a una part dels servidors o esclaus: són servidors en la mesura que esmercen el seu temps en la cura d'aquells a qui governen; o bé (2) la classe dels éssers humans pot dividir-se en servidors-esclaus $i$ homes lliures -dividint els homes lliures trobaríem el rei; o bé (3) tothom excepte el rei és esclau o servidor. Si fos així, però, ¿per què els éssers humans no es comptaven entre les possessions (del rei)? ${ }^{12}$

L'esclavitud serà, més endavant en el diàleg, el terme final d'aquelles ciutats que no han sabut entreteixir adequadament el seu material. El que ara se'ns mostra és que la situació dels esclaus no és gens clara. ${ }^{13}$ Els esclaus que abans podien incloure's entre les arts que contribuïen a la producció passen ara al context dels «servidors en general». Es tracta, doncs, d'examinar els servidors per destriar-ne el polític. $^{14}$

El Foraster vaticina (manteúomai) que entre els esclaus $i$ tots els altres servidors es mostraran aquells que es barallen amb els reis per posseir l'art principal (el d'enllaçar en el paradigma del tissatge). L'esment del teixit fa que no oblidem el paral $\bullet$ lel entre teixidor i rei, que serà especialment desenvolupat al final de la conversa (a partir de 305e). La resta, reitera el Foraster, ja han estat separats de la pràctica (práxeos) reial i política. El recurs del Foraster a la màntica o endevinació apareix en punts claus del diàleg. Ultra aquest que notem i l'anterior imatge del sacrifici ritual recent- ment comentada, recordem també la introducció del paradigma del paradigma (277d), la del tissatge (279) i quan demana «recordar» la gran reversió del cosmos (268es.). Sí que pot ser que «l'efecte immediat d'aquest llenguatge juganer és marcar com es pensava que seria d'inesperada la següent proposta per al jove Sòcrates» (MILLER, 2004, 82), però, a més, el que s'està jugant en tots els casos és, més aviat, una intuïció que no pot ser abastada pel mètode analític o que només pot presentar-se en cada intel•ligència particular.

El primer que es troba en aquest examen depuratiu dels servidors principals són aquells que tenen una ocupació i una vida ben contràries a allò que es podia esperar del polític: els esclaus, aquells que són comprats o adquirits. D'aquí, creiem, l'ambigua situació dels esclaus en la separació, ja que, d’una banda són «dignificats» en situar-los entre aquells que comparteixen una característica de la reialesa (el servei), però de l'altra són desplaçats com a «indignes» per la forma de vida que porten. Aquests no poden collaborar amb l'art reial. S. Benardete (1984 III, 123) treu dues conclusions de tot això: «El Foraster vol mostrar la ciutat bàsica essent totalment artificial i sense traces de vida en les seves possessions, i vol, en segon lloc, plantejar el problema de la llibertat de la manera més radical possible".

El Foraster continua la depuració entre els servidors. Curiosament, en la següent llista dels que es descarten (canvistes, comerciants, armadors o marxants), que el Foraster tampoc no creu que tinguin cap pretensió política, no es fa atenció a la rèplica del jove Sòcrates, que precisament pensa el contrari. El jove, evidentment, està pensant en la seva ciutat concreta, mentre que el Foraster està situat en el lloc teòric de la investigació segons el mètode separatiu. Afegeix aleshores que, pel que fa a la seva ocupació, és clar que cap d'aquests no hauria d'intervenir en política. Sense més comentaris, el que cal retenir és que apareix per primera vegada algú aportat pel jove que té pretensions de participació política -algú que creu tenir-ne el dret, diríem avui-, i que el Foraster despatxa ràpidament. S'hi refereix com aquells que «reben un sou o treballen a jornal». ${ }^{15}$ Si aquest és el cas, d'aquesta manera queda clar que no tenen, preo-
11.Skemp (1942 nota ad loc) troba digne de menció que Plató no consideri l'esclau com una eina 0 instrument viu com fa Aristòtil (Política I 3, 1253b28). Està classificat no com «instrument» sinó en la classe més aviat residual de possessions vives, com una mena de «criatura viva domèstica». La insinuació de 309a està d'acord amb això. Les lleis fan llum sobre el particular: l'esclau és una peça de la propietat i se suggereix que no està sempre domesticat (Les Lleis, 777; semblantment, la venda d'esclaus malalts està tractada legalment com la venda de mercaderies defectuoses a 915ess). Vegeu Sales \& Monserrat (2009).

12. Com nota Rosen $(1995,146)$; afegitó interessant: «Question: In wich segment of any of these diairesis is the philosopher to be found?».

13. En el Protàgoras Sòcrates seu tot ocupant el lloc d'un esclau per relatar la seva trobada amb el sofista d'Abdera (310a).

14. Skemp compara aquest text amb Gorgias 517bss on el polític s'ocupa de les necessitats físiques de la ciutat. El vertader polític sap realment el que cal. I afegeix: «Now, however, the phrase 'servant of the community' is given a higher sense. We must not be oblivious to the force and novelty of the change because we are tempted to be cynical about such 'ministers' after 2,500 years of experience».

15. La traducció de Balasch (1997) podria portar a confusió: fent referència a «soldats $i$

jornalers» sembla que s'estigui donant una altra llista d'oficis. No és així, sinó que es tracta d'una nova manera de referir-se als anteriors deixant clar que la política és una dimensió especial de la pólis que no pot estar lligada a aquells que actuen, que necessiten actuar, per un salari, sou o jornal. Una altra qüestió a debatre és aquesta: adonar-nos de com l'aspecte econòmic queda al marge de la «pura política». Discussió viva aleshores $i$ ara: o bé s'és prou lliure (ric?) com per tenir temps per dedicar-s'hi o bé hom s'hi dedica «professionalment». 
cupats com estan pels seus negocis, l'oci necessari per a dedicar-se a la política, sigui aquesta el que sigui (MONSERRAT, 2010).

Es continua després amb d'altres menes de diaconia o de servei. La primera és la dels que pertanyen al llinatge dels heralds (tò kerykiòn êthnos), entesos en escrits públics, que queda clar que no

16 Ens indica Accatino (1997, 128) que amb els heralds, a Atenes, els secretaris $i$ subsecretaris (grammateis hypogrammateis) prestaven el seu servei al Consell, al col•legi dels Tesmotetes. Cf. Hansen 1991, 2445, 123-4 respectivament) manen personalment en les ciutats tot $\mathrm{i}$ que hi tenen molt a veure. ${ }^{16}$ El Foraster mostra el seu convenciment de no anar errat en la recerca del polític cercant entre els servidors. Pot semblar fora de lloc, però s'insisteix en fer notar que la política té una certa dimensió de servei, ni que sigui adjunta, en la mesura que mirarà pel profit de la ciutat. Sigui o no sigui correcta la separació o dièresi que s'està fent, el que està quedant clar és que s'està procedint a la posició de les arts fonamentals indispensables per a la vida de la ciutat. Primer, la força del treball proporcionada pels esclaus; després, l'element indispensable per al comerç dels resultats d'aquest treball: canvistes, comerciants, marxants; després, la funció regulativa d'aquesta vida comercial a càrrec de «servidors civils» o heralds, que no manen personalment en la ciutat. El grup següent serà el de tot un conjunt de serveis que estan associats pròximament al reial: els endevins $i$ els sacerdots, l'element especialment religiós de la ciutat. El Foraster afegeix: «De manera que jo no he tingut una visió en somnis quan he dit que aquí probablement se'ns mostrarien aquells preferentment inclosos en la disputa a l'art polític. Per consegüent, pot semblar certament molt fora de lloc buscar en una part de l'art del servei» (290bc).

No creiem que sigui estrany que el Foraster passi de la separació dels esclaus, dels assalariats $i$ dels funcionaris, com a grup de servei econòmic de la ciutat, a la consideració del següent grup de servidors (endevins i sacerdots) fent referència a una «visió en somnis» (enúpnion). L'aclariment continua:

«FOR.- Doncs apropem-nos més a tocar amb els encara no examinats. N'hi ha alguns que participen d'un cert saber diaconal, car dominen l'art dels endevins: són vistos d'alguna manera com intèrprets dels déus per als homes.

SÒCR. J.- Sí.

FOR.- I hi ha encara el llinatge dels sacerdots, entès com diu la creença general, per part nostra, a oferir dons sacrificadors als déus tal com ells volen, i pel que fa a ells, a adreçar-los les pregàries que volen per a concedir-nos els seus favors. L'una i l'altra d'aquestes pràctiques són part d'un art diaconal. SòCR. J.- Sí que ho sembla.» (290cd)

Ben llegit, aquest retorn al polític està esdevenint una construcció de la ciutat a partir de l'anàlisi dels components que la fan possible des de la seva primera i confusa materialitat. Si hem començat per la possessió de matèries primeres, després s'ha passat a dilucidar allò que permetria la fabricació generadora, és a dir, els instruments, les eines; després, el que permet la conservació (els recipients), el transport, la protecció, la diversió i el nodriment. Obtinguda aquesta materialitat de la ciutat, el Foraster separa, d'entre els servidors de la ciutat, els esclaus, comerciants, funcionaris, endevinadors i sacerdots. Anant a la recerca del polític destriem els constituents de la pólis.

\section{§3. Valoració i ruptura de la dièresi}

¿Per què la divisió avança per les causes auxiliars quan sembla clar que el polític hauria d'estar en les principals? K. Dorter mostra que el problema queda desdibuixat si es té present el següent: les línies embolicades de la derivació il •lustren un problema important. Totes les coses estan relacionades les unes amb les altres de maneres molt diverses (no hi pot haver un mapa conceptual definitiu de la realitat) i la «via llarga» de la dièresi insisteix encara en una mena simple $\mathrm{i}$ determinada de derivació. L'embolic present sorgeix perquè el Foraster abandona la pulcritud artificial de les divisions d'El sofista i mostra la multiplicitat de relacions introduïnt més d'una línia de derivació a la vegada (DORTER, 1994, p. 214-215). Així, els animals de ramat poden classificar-se sota els animals o sota les possessions; els esclaus són a la vegada espècie de les possessions i dels servidors; i el polític esdevé d'una banda un senyor i de l'altra un servidor, en un sentit una causa primera però en un altre una causa auxiliar (cf. 287d). La dificultat estava prefigurada en la dièresi del pastor, on els ocells estaven entre 
els animals de dos peus, animals terrestres, o en El sofista que apareixen com a animals aquàtics; o en la del tissatge, on no només cardar i combinar eren ambdós parts de dues arts contradictòries, sinó que el tissatge mateix esdevenia una espècie de l'art de fer la roba, quan només en part està relacionat amb la confecció de roba. Vegeu al respecte, Dorter (1994, p. 215). En conclusió, la realitat no es deixa atrapar per l'anàlisi. Encara més, respecte de la divisió entre causes i concauses (o causes auxiliars), resulta que ara s'ha produït una variació, car s'ha parlat de possessions i serveis. Les possessions són les causes auxiliars $i$ entre els servidors es disputen el lloc al veritable polític. El primer que queda descartat és la dimensió material, i el servei resulta una dimensió més propera a la política.

El Foraster, emprant una imatge cinegètica, diu que sembla que es toca un cert rastre d'allò vers el qual es marxa (PASCUAL, 2013). El que ha trobat és que la dignitat sacerdotal esdevé molts cops associada a la reial, com a Egipte. ${ }^{17}$ Sense haver d'anar tan lluny, l'altre cas és el d'Atenes mateixa. En ella es tria per sorteig aquell que ocuparà la magistratura de l'arcont rei, l'encarregat dels sacrificis locals més antics i venerables, herència de l'antiga reialesa. Aquesta referència del Foraster a l'arcontat és acceptada pel jove sense cap comentari per part seva. Assistim, cal notar-ho, a un moment de notable càrrega dramàtica. En primer lloc, per allò no dit: és precisament davant l'arcont rei que Sòcrates vell s'acaba de presentar la vigília anterior per saber del cas instigat en contra seu, acusació que el durà al judici i a la mort (Teetet 210d i Eutifró 1a). L'arcont rei era el magistrat que entenia com a president del tribunal en els casos d'impietat $i$ de sacrilegi -casos que no eren estranys $i$ on es debatien les més greus tensions de la ciutat. Ningú no diu res de tot això i Sòcrates segueix present en el seu impertorbable silenci. Cal afegir, encara, que, segons com, el vell Sòcrates ha semblat un endeví, o un bruixot, o ha gaudit de certes premonicions gràcies al seu daimon. ${ }^{18}$

La càrrega dramàtica s'accentua, en segon lloc, pel context: retinguem un moment que en aquesta secció -on no es divideix pel mig, sinó a la manera d'una víctima sacrificial- el Foraster ha endevinat alguna cosa, primer com en somnis, tot $i$ que després es veu que no és pas un somni. Estem assistint, per a arrodonir aquest moment del relat tenyit de «sagrat», a una mena de visió. Aquesta visió continua encara amb el que es diu seguidament, quan s'afirma que hem de considerar distints dels anteriors aquests reis i sacerdots nomenats per sorteig, els seus servidors i també gran quantitat $d^{\prime}$ altres que ara s'apareixen. El jove no sap a què es fa referència i, a més, el Foraster els qualifica de ben estranys (atópous), perquè:

«el seu llinatge és compost de molts gèneres, com es mostra immediatament a qui l'examina. Perquè molts $d^{\prime}$ aquests homes s'assemblen a lleons i a centaures ${ }^{19} i$ altres a éssers per l'estil, molts d'ells a sàtirs, a éssers dèbils $i$ a animals multiformes ${ }^{20}$ : sovint canvien d'unes figures i propietats envers unes altres. Ras i curt, Sòcrates, jo crec que ara he entès els homes» (291ab).

Assistim a un moment culminant carregat de sàtira i de menyspreu. No és balder que el Foraster s'adreci al jove pel nom quan adverteix del perill del govern sense coneixement $i$ dels perills del govern a partir d'una falsa possessió de coneixement. Retinguem d'aquesta primigènia descripció la «multiplicitat de gèneres», la seva «multiformitat» i també la seva capacitat de «canviar de figures i propietats». És prou clar que la imatge coincideix amb la figura dels polítics contemporanis $i$ les imatges estan relacionades amb els diferents tipus polítics, com en els llibres VIII i IX de La república. ${ }^{21}$ Fixem-nos ara què és el que respon el jove interlocutor quan el Foraster afirma que és ara que ha comprès els homes: Sòcrates li demana que parli, que sembla que hagi vist quelcom estrany (atopón; de l'atopia també se n'ha parlat abans en la descripció del paradigma del paradigma, cf. 277d5). El Foraster li dóna el motiu de la seva estranyesa: és aquella que prové de la ignorància (tò gàr átopon ex agnoías pâsi symbaínei). Tot i que aquesta visió sembla que ha estat anterior, el Foraster encara ara experimenta l'estranyesa. Va dubtar en el mateix moment que va adonar-se de la multitud (del cor) que s'ocupa dels afers de la ciutat. ${ }^{22}$

Seguim amb la caracterització. Els que
17. Sobre aquesta suposada norma, vegeu Skemp 1942, 190n.1. En canvi, Samb (1995) ha estat el darrer a sostenir que Plató coneixia prou bé Egipte. La qüestió ha estat reiteradament discutida. Vegeu, per exemple, Moret (1902), Schwaller (1961), Griffiths (1965), Brisson (1982). 18. El primer cas en el Teages. El segon en el Menó 80d. El tercer, per exemple, en els Records de Sòcrates de Xenofont. Cf. Grimaldi 2004.

19. Imatges del thymós $i$ l'epithymía excessius a La república $588 \mathrm{~s}$.

20. Òbviament també és fàcil de relacionar amb els camaleons de la política, que representarien els polítics de la democràcia, on els càrrecs «es canvien d'unes figures, etc.». Polytrópois és aplicat per Homer a Ulisses, autoidentificació típica de Sòcrates en els diàlegs platònics. Cf. Rosen (1995, p. 148). Aquesta és la qüestió d'El sofista i El polític, és a dir, sota quines aparences es mostra el filòsof.

21. Accatino (1995, p. 203-212) en fa una interpretació diferent: la intercanviabilitat correspon a quan oradors, generals i jutges ocupen altres papers dels que els pertoca, contrariant el manament de $L a$ república.

22.291c: cal notar que apareix un terme que en altres llocs platònics gaudeix de molta importància: exaíphnes (de sobte, en el mateix moment). Altres aparicions en La república, El convit, Menó, la Carta VII. En El polític el terme acompanya una situació cognoscitiva semblant a les citades, la mostració de la veritat. Segons Dorter $(1994,46)$ és un terme que esdevé de crucial importància en la segona part del Parmènides. N'havia destacat la importància Sales (1992, 122-194). 
s'ocupen de les coses de la ciutat són un cor. La política esdevé imaginada en la metàfora teatral: els polítics actuals, suggereix el text, no són altra cosa que «imitadors» (cf. 303c) que ocupen un paper en els règims que no són el vertader règim polític correcte. Aquest cor és nombrós i variat, i el text encara ho detalla més:

«FOR.- El més gran màgic de tots els sofistes $i$ el més experimentat en aquestes arts, que nosaltres, per difícil que sigui distingir-lo dels homes veritablement reials, dels polítics, de tota manera l'hem de separar si volem veure clar el que ara investiguem. ${ }^{23}$

SÒCR. J.- D'això no podem desdir-nos-en de

23. Segons nota Balasch: sofis i mag La república 598, El sofista 234c-235a; sofista i rètor Gòrgias 520a; rètor i polític Fedre 258ab.

24. A La república 429ass, se sosté que els més grans sofistes no són els sofistes professionals, sinó els ciutadans reunits en assamblees, tribunals teatres. Sobre el sofista com a dissimulador, vegeu El sofista 267 a ss., on a $268 \mathrm{~b}$ el parent proper del vertader sofista és aquell que dissimula en públic amb llargs discursos. El nom que se'ls dóna en el diàleg no és el de «polític» sinó el d'«orador popular». Cf. Notomi 2010.

25. Rosen, 1995, 149: «The genuine statesman is not a person or a human being at all, but rather phronesis. The genuine regime is therefore not a regime at all because it lacks a constitution or both written and unwritten laws. The stranger will defend the paradoxical conclusion that nomos is the image of phronesis.) 26. Constitució d'Atenes 3, 2. Polemarc és el fill de Cèfal que recull l'herència paterna quan aquest abandona l'escena per tal de fer sacrificis al déus, en el llibre primer de La república. reis arconts. ${ }^{26}$ És aleshores que el sacerdot és relegat a un lloc subordinat en la ciutat, disminuint així l'autoritat tradicional. És en el moment de feblesa de les institucions tradicionals que s'esdevé per a la ciutat el moment d'obertura de la qüestió del tipus de règim que cal establir. Si l'autoritat tradicional no hagués estat inoperant, o si el vertader polític hagués fet acceptar les seves credencials, diu S. Benardete (1984 III, p. 124) que aquell qüestionament no hauria existit mai. Aquest moment de feblesa és el moment òptim per a l'aparició de la figura del sofista embaucador, d'aquell que diu posseir l'art de governar, però també ho serà de la possibilitat de renovació política. La ciutat es mou entre aquests dos pols, el sagrat i la tècnica, que en el nostre diàleg estan respectivament representats per les figures del pastor i del tissatge debatent-se entre els règims possibles ben o mal exercits. Resulta, doncs, que és en la ciutat on el rei sacerdot ja ha perdut la seva autoritat que s'obre l'oportunitat de pensar quines són les possibilitats constitucionals que es presentarien; de la mateixa manera passa com, en el mite, quan els genis divins cal que es retirin del món per a possibilitar l'autonomia humana. Aquest és un dels paral•lels estructurals que configuren la forma constructiva del diàleg.

El diàleg avançarà a partir d'ara fins 303b7 amb la funció d'explicar per què els polítics dels règims històricament existents no poden ser considerats vertaders polítics i s'han de deixar al marge en l'anàlisi que determinarà el vertader polític.

$* * *$

Recapitulem: el «retorn al polític» ha anat acomplint aquestes passes. En un primer moment s'ha abandonat la «precisió» del mètode de la dièresi passant de tallar pel mig a tallar per les juntures en el menor nombre possible. Aquest canvi metodològic que pot valorar-se com una pèrdua de precisió pot ser també un guany en tant que respecta la realitat en la seva composició natural. En un segon moment, s'ha procedit a una aproximació al polític, que havia quedat «abandonat» després del mite, partint les causes auxiliars de la ciutat per tal de destriar-lo (com s'havia fet amb el tissatge). El resultat ha estat el refús d'una sèrie d'elements constitutius de la ciutat en un grau cada vegada més «polític»: d'entrada en la Constitució d'Atenes que el càrrec de polemarc fou instituït per la feblesa demostrada per un dels 
l'element constitutiu material de la ciutat, el seu cos, (matèries primeres, eines, recipients, vehicles, protecció, diversió, nodriment); després van separant-se els elements que col•laboren en l'ordenació d'aquest cos (esclaus-força de treball, comerciants, funcionaris públics, endevins, sacerdots). En un tercer moment, un cert rastre ha portat al Foraster a endevinar que apareixen en aquest moment aquells que disputen amb el rei pel govern de la ciutat: els més grans sofistes que semblen posseir el que només el vertader polític posseeix, el saber polític. El que s'esdevindrà a continuació, l'anàlisi de les formes de govern, es dóna com a moment crític de la ciutat que veu com cauen les seves tradicions sagrades (arcont-rei) i es disputen entre els que aparenten sabers de govern: és el moment del qüestionament del tipus de règim a establir. L'establiment posterior de cinc tipus de règims possibles determinant com a condicions efectives quants governen i de quina manera ho fan. Certes imprecisions (la democràcia indivisa, el paper del saber) porten a preguntar on està situat el saber de la ciutat.

El resultat d'aquest «retorn», doncs, podem veure'l com una construcció de la pólis a partir dels seus fonaments elementals fins al moment en què, sotmesa a la crisi en la creença religiosa que la sostenia, o sigui, abandonada pels déus, permet l'aparició del lloc d'un saber polític possible, lloc, però, que serà ocupat d'antuvi per diferents feres $i$ diferents formes de règims.

\section{Nota bibliogràfica}

El text grec correspon al de l'edició PLATONIS, Opera I: Tetralogias I-II continens. recognoverunt brevique adnotatione critica instruxerunt $E$. A. Duke, W. F. Hicken, W. S. M. Nicoll, D. B. Robinson et J. C. G. Strachan. Oxford, 1995. La traducció dels fragments d'El polític descansen en les versions catalana de Manuel Balasch (PLATÓ (1997), Diàlegs. XVII: El polític. Edició del text grec, traducció i estudi introductori de M. Balasch. Barcelona, Fundació Bernat Metge), portuguesa de Carmen Soares (PLATÃo (2008), 0 Político. Tradução do grego, introdução e notas de Carmen Isabel Leal Soares. Lisboa. Circulo de Leitores e Temas \& Debates), i espanyola de Fran- cesc Casadesús (PLATÓN (2008), Critón. El político. Traducción, introducción y notas de Francesc Casadesús Bordoy. Madrid, Alianza). Hem tingut també en compte les edicions i traduccions de P. Accatino: PLATONE (1997). Politico. traduzione e introduzione di P. Accatino. Bari, Laterza; BENARDETE, S. (1984). Plato's Statesman - Part III of The Being of Beautiful. Chicago \& London, University of Chicago Press; BRISSON, L. ; PRADEAU, J.-F. (2003). Platon. Le politique. Paris, GF Flammarion ; CAMPBELL, L. (1867). The Sophistes and Politicus of Plato. Oxford, Clarendon Press; DIES, A. (1935). Platon: Oeuvres Complètes IX/1, Le politique. Paris, Les Belles Lettres; MIGLIORI, M. (2001) Platone. Politico. Milan, Bompiani; ROBIN, L. (1942). Platon. Politique en Platon. Oeuvres Complètes. Paris, Gallimard; ROWE, C.J. (1995). Plato, Statesman. Warminster, Aris \& Philips; SANTA CRUZ, M. I. (1998) Platón. Político, en Platón. Diálogos. Madrid, Gredos. v. V; SKEMP, J. B. (1952/ 1987). Plato's Statesman. New Haven / Bristol, Classical Press.

\section{Obres citades}

ACCATINO, P. (1997) L'arkhé del Politico. In: ROWE, C. J. (ed.) (1995) Reading the Statesman. Proceedings of the Symposium Platonicum III. Sankt Agustin, Academia Verlag, p. 203-212.

BALASCH, M. (1997) Plató. Diàlegs. XVI: El Polític. Barcelona.

BENARDETE, S. (1984) The Being of Beautiful: Plato's Theaetetus, Sophist and Statesman. Chicago.

BRISSON, L. (1982) Platon, les motes et les mythes. Paris.

CROMBIE, I. M. (1962) Análisis de las doctrinas de Platón, 2 vols., Madrid 1979.

CROSSMAN, R.H.S. (1937) Plato Today, London.

DORTER, K. (1994) Form and Good in Plato's Eleatic Dialogues. Berkeley/ Los Angeles/London.

FRIEDLÄNDER, P. (1960) Platon III: Die platonischen Schriften Zweitte und Dritte Periode, Berlin, Walter de Gruyter, 1960 (2a ed.)

GOLDSCHMIDT, V. (1947) Les Dialogues de Platon. Structure et Méthode Dialectique. Paris.

GRIFFITHS, J. G. (1965) Plato on Priests and King in Egypt, Classical Review, v. 15, p. 156-157.

GRIMALDI, N. (2004), Socrate le sorcier, Paris.

GRISWOLD, C. (1995) Le libéralisme platoniciene: de la perfection individuelle comme fondament d'une théorie 
politique. In: DIXSAUT, M. (ed.) (1995) Contre Platon II: Le platonisme renversé, Paris, p. 155-195.

HANSEN, M. H. (1991) The Athenian Democracy in the Age of Demostenes. 0xford.

LISI, F. (1989), La clasificación de los estados en la teoría política platónica, Memorias de Historia Antigua, v. 10, p. 23-43.

MILLER, M. (2004) The Philosopher in Plato's 'Statesman', Las Vegas: Parmenides Pub.

MONSERRAT, J. (2003) La mesure comme principe constitutif du Politique de Platon, Revue de Philosophie Ancienne, v. XXI, n. 1, p. 3-22.

MONSERRAT, J. (2011) Procesos cognitivos y crítica política: ¿una política ilustrada en sentido platónico?, Crítica, v. 129, p. 31-52.

MONSERRAT, J. \& SALES, J. (2010) La excepcionalidad de la areté gorgiana. Sobre la necesidad de una revisión de las determinaciones de la concreción política aristotélica, Pensamiento, v. 66, n. 247, p. 35-54.

MORET, A. (1902) Du caractère sacré de la royauté égyptienne. Paris.

NOTOMI, N. (2010) La unitat del 'Sofista' de Plató. Entre el Sofista i el Filòsof. Barcelona.

PASCUAL, A. \& MONSERRAT, J. (2013). ¿Y por qué

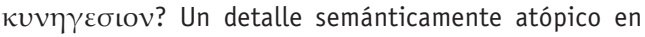
Protágoras (309a1-2), Euphrosyne (in print).

ROSEN, S. (1995) Plato's Statesman. The Web of Politics. London, New Haven \& London.

ROWE, C. J. (ed.) (1995) Reading the Statesman. Proceedings of the Symposium Platonicum III. Sankt Agustin, Academia Verlag.

SALES, J. (1992) Estudis sobre l'ensenyament platònic: (I) Figures i Desplaçaments. Barcelona, Anthropos.

SALES, J. \& MONSERRAT, J. (2009). A more political animal than bees. Polity as an intermediate State, as the Highest State, or as an agent of stability, Studia Neoaristotelica, v. 6, n. 1 , p. 3-14

SAMB, D. (1995). Le Politique 290d-e. In: ROWE, C. J. (ed.) (1995) Reading the Statesman. Proceedings of the Symposium Platonicum III. Sankt Agustin, Academia Verlag, p. 333-336.

SANTA CRUZ, M. I. (1998) Platón. Político, en Platón. Diálogos. Madrid, Gredos. v. V.

SCHRÖDER, M. (1935) Zum Aufbau des platonischen Politikos. Jena, Universitäts-Buchdruckerei.

SCHWALLER, R. A. (1961) Le roi et la théocratie pharaonique. Paris, Flammarion.

SKEMP, J. B. (1942) The Theory of Motion in Plato's Later Dialogues. Cambridge, Cambridge University Press.

Recebido em março de 2013 aprovado em junho de 2013. 